\title{
CLASSIFICAÇÃO DE IMAGENS DE SATÉLITE E ÍNDICES ESPECTRAIS DE VEGETAÇÃO: UMA ANÁLISE COMPARATIVA
}

Paulo Roberto Fitz ${ }^{1}$

Resumo: Estudos relativos à dinâmica territorial sempre ocuparam papéis de destaque no âmbito da Geografia. As alterações espaciais experimentadas em determinadas regiões estão diretamente ligadas aos cenários físicos, políticos, econômicos, culturais e ambientais desses espaços em um dado momento. Diversas ferramentas têm sido utilizadas para analisar o cenário de um determinado ambiente. O presente estudo teve como objetivo verificar a existência de correlação entre uma imagem Landsat classificada por um método de classificação supervisionada e diferentes índices de vegetação (IVs), a saber, SR, IVR, NDVI e SAVI, no município de Mundo Novo, no estado de Mato Grosso do Sul. Para tal, foram utilizados o software livre QGIS e a planilha Excel da Microsoft. Como resultado, verificou-se haver correlação de média a alta entre os distintos IVs e a imagem classificada.

Palavras-chave: Sensoriamento remoto. Índices de vegetação. Classificação de imagens. Correlação entre imagens.

\section{SATELLITE IMAGE CLASSIFICATION AND SPECTRAL VEGETATION INDICES: A COMPARATIVE ANALYSIS}

Abstract: Territoriality studies always occupied prominent roles in the field of geography. The spatial changes experienced in certain regions are directly linked to the physical, political, economic, cultural and environmental scenarios of these spaces at any give time. Several tools have been used to analyze the scenario of an especific environment. This study aimed to verify the existence of a correlation between a Landsat image classified by a supervised classification method and different vegetation indexes (VIs), that is, SR, IVR, NDVI and SAVI, in the municipality of Mundo Novo, in the state of Mato Grosso do Sul. For this, we used the software free QGIS and Microsoft Excel spreadsheet. As a result, there was a medium to high correlation between the different VIs and the classified image.

Keywords: Remote sensing. Vegetation indices. Image classification. Correlation between images.

\section{CLASIFICACIÓN DE IMÁGENES DE SATÉLITE Y ÍNDICES ESPECTRALES DE VEGETACIÓN: ANÁLISIS COMPARATIVO}

Resumen: Los estudios relacionados con la dinámica territorial siempre han ocupado roles prominentes en el campo de la geografía. Los cambios espaciales experimentados en ciertas regiones están directamente vinculados a los escenarios físicos, políticos, económicos, culturales y ambientales de estos espacios en un momento dado. Se han utilizado varias herramientas para analizar el escenario de un entorno dado. El presente estudio tuvo como objetivo verificar la existencia de una correlación entre una imagen Landsat clasificada por un método de clasificación

1UFGD, PPGG, Laboratório de Geografia Física, Dourados, Brasil, paulo.fitz@gmail.com, https://orcid.org/0000-0002-5099-0677 
supervisado y diferentes índices de vegetación (IVs), a saber, SR, IVR, NDVI y SAVI, en el municipio de Mundo Novo, en el estado de Mato Grosso do Sul Para este propósito, se utilizaron el software gratuito QGIS y la hoja de cálculo Microsoft Excel. Como resultado, hubo una correlación media a alta entre los diferentes IVs y la imagen clasificada.

Palabras clave: Teledetección. Índices de vegetación. Clasificación de imágenes. Correlación entre imágenes.

\section{INTRODUÇÃO}

Ferramentas como o Sensoriamento Remoto (SR) vêm sendo utilizadas para analisar, interpretar e compreender o cenário de um determinado território num dado período de tempo. Imagens provenientes de sensores instalados em satélites orbitais são alguns dos produtos que podem ser utilizados para trabalhar a dinâmica da superfície terrestre. Considerando que a radiação solar incidente no planeta é do tipo eletromagnética (REM), ou seja, possui características físicas próprias como absorção, reflexão e transmissão de energia (FITZ, 2008, p.100), a possível captura de tais atributos pode servir para estudar diferentes feições na superfície. Os diversos comprimentos de onda insertos em imagens de satélite proporcionam análises diferenciadas, uma vez que permitem a visualização de porções de dentro e de fora da faixa do visível do espectro eletromagnético.

As faixas ou bandas relativas ao comprimento de onda do infravermelho, por exemplo, são largamente utilizadas em trabalhos de sensoriamento remoto por estarem associadas à emissão de calor (FITZ, 2008, p. 103). Assim, diferentes feições terão distintas respostas espectrais em função de suas próprias propriedades físicas. A reflectância espectral da cobertura vegetal é comumente analisada através de índices de vegetação (IVs). Estes, por sua vez, conforme Xue; Su (2017, p. 1), utilizam algoritmos personalizados que combinam matematicamente as radiações de luz visível e radiações do espectro não-visível. As porções mais utilizadas dizem respeito às regiões do vermelho e do infravermelho próximo e médio, uma vez que tais faixas espectrais "contêm a maior variação de resposta espectral para a vegetação" (OLIVEIRA et al., 2007, p. 1).

Como se pode depreender, os índices de vegetação são de larga utilização para fins de pesquisa, planejamento e monitoramento da superfície terrestre, em especial quando de estudos ambientais. Esse monitoramento faz uso de IVs como medidas precisas dos padrões espaciais e temporais da atividade fotossintética da vegetação (HUETE et. al., 1997, p. 40). 
Os cálculos envolvendo tais índices dizem respeito à reflectância da vegetação com relação ao espectro eletromagnético, isto é, às suas características químicas e morfológicas. O comportamento espectral dos vegetais está, assim, relacionado à composição química e da estrutura interna das folhas que os compõem. A reflectância das folhas na região do visível do espectro, dada pela absorção da radiação solar pelos pigmentos dos cloropastos, é mais baixa do que na região do infravermelho próximo, em função do espalhamento da radiação solar no mesófilo (OLIVEIRA, 2007, p. 1).

Dessa forma, pesquisadores têm combinado dados das bandas do infravermelho e do vermelho para analisar a cobertura vegetal, o que é criticado por Xue; Su (2017, p. 2) por usar um pequeno grupo de bandas para detectar, por exemplo, a biomassa da vegetação. Adiante, os autores sustentam que, assim mesmo, o uso de um algoritmo de IV pode ser uma boa ferramenta para estudos dessa natureza. Ressaltam, ainda, que se deve ter em conta a diversidade dos ambientes, uma vez que cada caso é um caso, o que exigiria readequação do IV em função de suas características próprias. (XUE; SU, 2017).

Essas considerações se fazem interessantes na medida em que muitos usuários têm utilizado tais indicadores como "verdade absoluta", ou seja, como se retratassem fielmente as características da vegetação de qualquer ambiente. $O$ índice mais utilizado, o NDVI, por exemplo, é muito sensível ao solo, o que levou pesquisadores a desenvolver IVs alternativos. (SCHMIDT; KARNIELI, 2001)

Em função de suas propriedades físicas, a vegetação densa tem baixa reflectância no vermelho e apresenta alta correlação com o IAF - Índice de Área Foliar, que pode ser entendido como sendo a área ocupada pelas folhas de uma vegetação por unidade de área (XUE; SU, 2017). Os diferentes índices de vegetação criados procuram, portanto, satisfazer às necessidades do usuário em dada situação.

Diversos autores têm trabalhado com essa temática. Muitas das pesquisas voltam-se para o uso de um ou mais IVs com a decorrente comparação, como nos casos de Rêgo et al. (2012); Oliveira et al.(2007), Almeida; Fontana (2009) Nonato; Rodrigues (2009) e Hentz et. al.(2014), entre outros.

Uma vez que os distintos IVs fornecem diferentes escalas de valores em função de suas concepções e aplicações, a ideia era a de realizar uma comparação dos mesmos com uma imagem classificada. Demarchi; Piroli; Zimback (2011) apresentam uma tentativa de comparar dois IVs (NDVI e SAVI) com uma 
classificação supervisionada pelo método de máxima verossimilhança, procedimento semelhante ao ora realizado.

Para Fitz (2008, p. 129), “a classificação de uma imagem nada mais é do que a identificação de determinados elementos nelas presentes através da associação de cada um de seus pixels a uma determinada classe pré-estabelecida." Já Richards e Jia (2006) apresentam que a classificação de uma imagem realizada em um sistema pode ser entendida como um método em que são atribuídos valores específicos (rótulos) aos pixels de acordo com sua resposta espectral. Assim sendo, deve-se ter cuidado para o fato de que, como é alertado por Crósta (1993, p. 63), em relação à escolha das bandas espectrais utilizadas para a classificação, deve-se realizar uma cuidadosa seleção das mesmas "para que a combinação de 3 bandas contenha a informação espectral realmente desejada."

Levando em consideração tais apontamentos, foi realizada uma comparação dos IVs com a imagem classificada por um método de classificação supervisionada. Em seguida, seguindo a hipótese de que deveria haver forte correlação entre tais elementos, foram analisados os dados relativos aos mapas temáticos gerados. Todas as comparações foram realizadas para os anos de 1985 e 2018, a fim de que se pudesse ter uma compreensão melhor das confrontações.

A área selecionada para a realização do estudo abrangia a superfície do município de Mundo Novo (Figura 1), no Estado do Mato Grosso do Sul. A escolha do município em questão se deu pela disponibilidade de imagens do mesmo e em função de pesquisa realizada pelo autor junto ao Programa de Pós-Graduação em Geografia e ao Laboratório de Geografia Física da Universidade Federal da Grande Dourados intitulada "Análise comparativa de dados georreferenciados na dinâmica do território da fronteira Brasil (MS)-Paraguai”. Mundo Novo insere-se na área então examinada e possui os atributos considerados preponderantes para a presente experimentação, a saber, uma boa mescla das feições traduzidas pelas classes a serem trabalhadas: áreas com vegetação original ou nativa, ambientes que sofreram alterações antropogênicas e volumosos cursos d'água.

A superfície ocupada pelo município, segundo o ZEE (Zoneamento EcológicoEconômico) do Mato Grosso do Sul publicado em 2009, está inserida na "Zona Ecológico-Econômica Iguatemi” (MATO GROSSO DO SUL, 2009). Esta zona originalmente apresentava, predominantemente, atributos do Bioma da Mata Atlântica, caracterizado por apresentar formações florestais como a floresta estacional decidual e semidecidual. As idas a campo corroboraram o fato de que, 
hoje em dia, a paisagem apresenta-se bastante alterada em função, especialmente, da expansão agropecuária na região.

Figura 01 - Mapa de localização de Mundo Novo

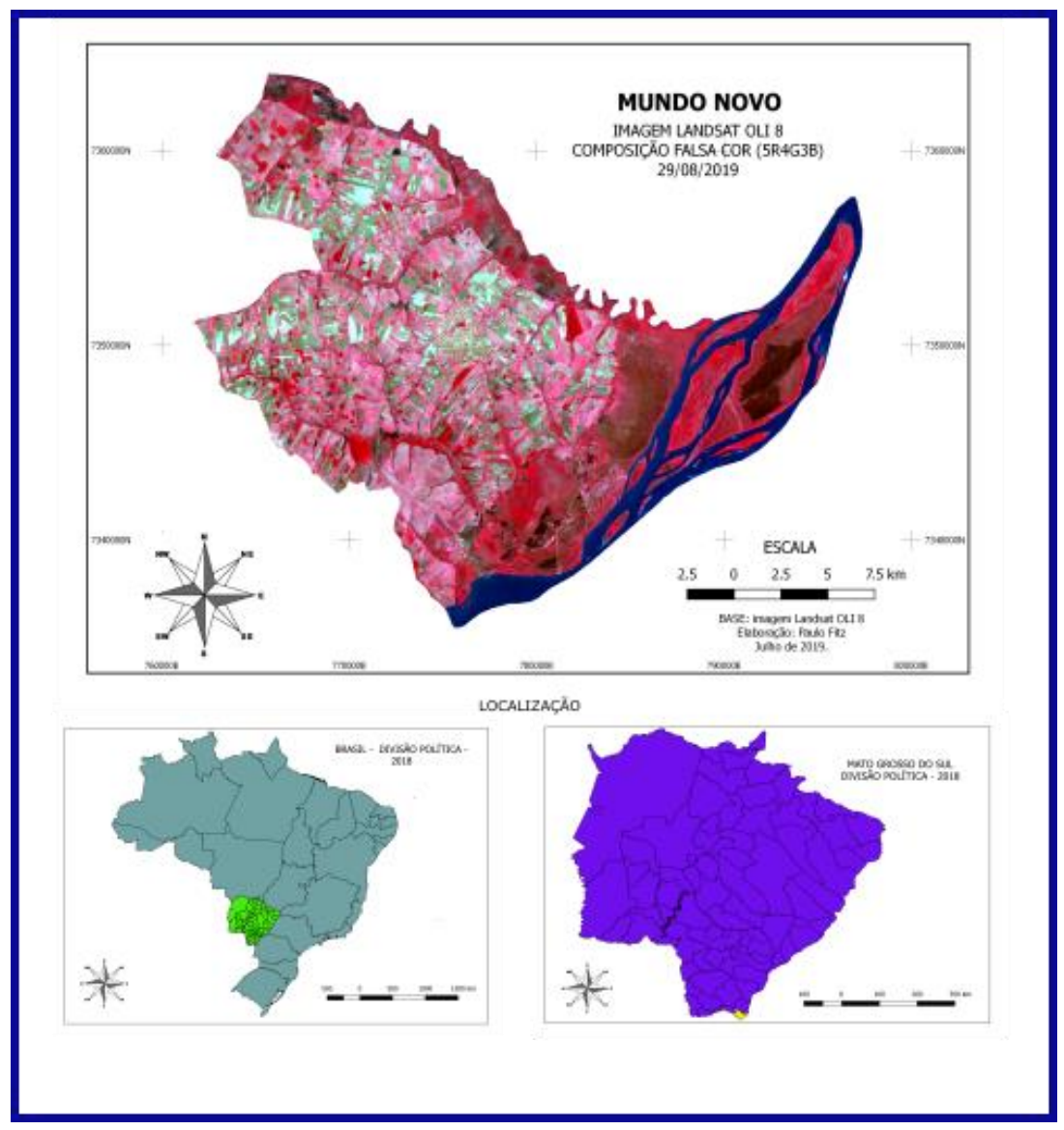

Fonte: Autor (2019).

De acordo com os dados do IBGE, em 2010 o município contava com 17.043 habitantes distribuídos em uma área de 477,8 km² (IBGE, 2010). Conforme dados dos Censos Agropecuários, o Município de Mundo Novo possuía, em 2006, 618 propriedades rurais contemplando $310,3 \mathrm{~km}^{2}$. Em 2017 passou a contar com 424 propriedades as quais ocupavam uma área de 342,2 km². (IBGE, 2006; 2017)

Os dados apresentados procuraram fornecer uma visão generalista da área de trabalho constituída, basicamente, por pequenas ou médias propriedades rurais. Em seguida partiu-se para a execução do objetivo central do presente estudo, isto é, o de comparar, a partir de imagens de satélite que cobrissem a superfície do município, a existência de correlação entre diferentes índices de vegetação (SR, IVR, NDVI e SAVI), e uma imagem classificada do mesmo. Dessa forma, os IVs deverão ser calculados para a obtenção dos mapas relativos aos seus usos, bem como os valores relativos aos coeficientes de correlação entre os IVs e a imagem classificada. Finalmente, a partir dos dados encontrados, deverão ser tecidas 
análises relativas aos mesmos.

\section{METODOLOGIA}

A execução do trabalho se deu a partir do descarregamento gratuito dos arquivos com as imagens do município escolhido desde o site da USGS (United States Geological Survey - Pesquisa Geológica dos Estados Unidos) e do INPE (Instituto Nacional de Pesquisas Espaciais) do Brasil. Optou-se pelo uso das imagens do instrumento TM (Thematic Mapper) do Landsat $5(22 / 08 / 1985)$ e do sensor OLI (Operational Land Imager) do Landsat 8 (de 29/08/2018), uma vez que ambos possuem várias faixas ou bandas espectrais com comprimentos de onda semelhantes e idênticas resoluções espaciais. O quadro 1 apresenta uma síntese dos sensores utilizados e algumas de suas características.

As imagens escolhidas eram do mês agosto, época que coincide, em especial, com o final da colheita do cultivo de milho e preparo para o plantio de soja na região. Nestas condições, o solo exposto e as áreas em preparo destacam-se em relação às áreas florestadas e de outras lavouras, o que facilita a interpretação e classificação das imagens.

Quadro 01 - Sensores e suas características

\begin{tabular}{|c|l|l|l|c|}
\hline SATÉLITE & SENSOR & \multicolumn{1}{|c|}{$\begin{array}{c}\text { BANDAS } \\
\text { ESPECTRAIS }\end{array}$} & $\begin{array}{c}\text { RESOLUÇÃO } \\
\text { ESPECTRAL }\end{array}$ & $\begin{array}{c}\text { RESOLUÇÃO } \\
\text { ESPACIAL }\end{array}$ \\
\hline \multirow{4}{*}{ LANDSAT 5 } & \multirow{4}{*}{ TM } & AZUL (B1) & $0,45-0,52 \square \mathrm{m}$ & \multirow{2}{*}{$30 \mathrm{~m}$} \\
\cline { 3 - 4 } & & VERDE (B2) & $0,52-0,60 \square \mathrm{m}$ & \\
\cline { 3 - 4 } & & VERMELHO (B3) & $0,63-0,69 \square \mathrm{m}$ & \\
\cline { 3 - 4 } & & IVP (B4) & $0,76-0,90 \square \mathrm{m}$ & \\
\hline \multirow{3}{*}{ LANDSAT 8 } & \multirow{3}{*}{ OLI } & AZUL (B2) & $0,45-0,51 \square \mathrm{m}$ & \multirow{2}{*}{$30 \mathrm{~m}$} \\
\cline { 3 - 4 } & & VERDE (B3) & $0,53-0,59 \square \mathrm{m}$ & \\
\cline { 3 - 4 } & & VERMELHO (B4) & $0,64-0,67 \square \mathrm{m}$ & \\
\cline { 3 - 4 } & & IVP (B5) & $0,85-0,88 \square \mathrm{m}$ & \\
\hline
\end{tabular}

Fonte: https://landsat.gsfc.nasa.gov; http://www.dgi.inpe.br. Acessos em 22/01/2018 e 23/10/2018.

O tratamento das imagens foi realizado com o uso do software livre QGIS. As imagens foram reprojetadas para o sistema de referência atualmente em uso no Brasil, o SIRGAS 2000. Foram realizadas combinações coloridas "falsa-cor" 4R-3G2B para o Landsat 5 e 5R-4G-3B para o Landsat 8, a fim de se diferenciar bem a vegetação e os cursos d'água das demais feições. Neste tipo de combinação, a vegetação mais exuberante é visualizada por uma forte coloração avermelhada, enquanto que áreas com presença de lavouras e vegetação de pequeno porte são 
vistas com tons rosados claros. Áreas contendo solo exposto e vegetação seca apresentam tons cinza-esverdeados e corpos d'água são reconhecidos pela coloração azul. Procedeu-se, entrementes, à confecção de composições coloridas RGB para checagem de nuances. De igual sorte, foram realizadas saídas a campo para o monitoramento e controle da ocorrência dos diferentes usos da terra.

Para os cálculos relativos ao município trabalhado, foi criado um "polígono máscara" com base na divisão municipal disponibilizada pelo $\mathrm{IBGE}^{2}$. As imagens foram, então, recortadas a partir desse polígono para a realização dos posteriores cálculos de correlação.

Em um primeiro momento foi realizada a classificação das imagens a partir do algoritmo dzetsaka disponibilizado pelo QGIS. Trata-se de um método de classificação supervisionada desenvolvido por Nicolas Karasiak ${ }^{3}$, o qual utiliza um classificador GMM (Gaussian Mixture Model), ou Modelo de Mistura Gaussiana. Tais modelos podem ser entendidos como

famílias de distribuições formadas pela composição de mais de uma distribuição básica. Esses modelos são formados pela distribuição de probabilidade $D 1$ com probabilidade $w 1$, pela distribuição de probabilidade $D 2$ com probabilidade w2, etc.. No caso de uma mistura de Gaussianas, grupos são descritos estatisticamente pelos parâmetros média, $\mu$, e matriz de covariância, $\Sigma$. (PORTELA, 2015, p. 31)

Como foram utilizadas imagens de média resolução $(30 \mathrm{~m})$, optou-se pelo uso de apenas três classes de ocupação do solo. Estas foram escolhidas em função de suas características bastante visíveis nas imagens Landsat com tal resolução espacial:

- Classe 1: corpos d'água, que inclui todos os conjuntos de feições que caracterizem acumulação de água, como rios, lagos e açudes;

- Classe 2: ambientes antropizados, que dizem respeito às feições reconhecidas como aquelas alteradas pela ação do homem;

- Classe 3: cobertura vegetal "original", que engloba, além da vegetação nativa composta principalmente por mata atlântica e de várzea, porções com plantações de florestas de espécies exóticas, uma vez que, nesta escala, torna-se impraticável distinguir a introdução de tais matas.

Levando em consideração o colocado por Fitz et. al. (2019) e Eastman (1998), foram vetorizados 150 (cento e cinquenta) polígonos no total, isto é, 50 (cinquenta) áreas de treinamento para cada uma das três classes escolhidas que

\footnotetext{
${ }^{2}$ www.ibge.gov.br. Acesso em 22/03/2019.

${ }^{3}$ https://plugins.qgis.org/plugins/dzetsaka/. Acesso em 17/04/2019.
} 
deveriam contemplar, pelo menos, 30 (trinta) pixels cada. A classificação realizada, tida como situação "mais próxima da realidade", deveria servir de padrão para a análise dos IVs, ou seja, ela desempenharia o papel de parametrizar as correlações realizadas.

Atingida esta etapa, foram geradas imagens a partir dos IVs computados desde a "calculadora raster" presente no QGIS para os anos de 1985 e 2018. Preliminarmente foram utilizados o SR (Índice de Vegetação da Razão Simples) e seu inverso, o IVR (Índice de Vegetação da Razão). Estes índices possuem boa correlação com a biomassa vegetal e são bastante utilizados para estimá-la e monitorar a cobertura vegetal de alta densidade. Posteriormente foi calculado o NDVI (Índice de Vegetação Normalizado), um dos mais conhecidos e aplicados, para, finalmente, ser utilizado o SAVI (Índice de Vegetação Ajustado ao Solo), cuja formulação, semelhante ao NDVI, busca corrigir o efeito do solo naquele índice.

Após a realização dos cálculos dos IVs, foi utilizada a ferramenta do QGIS/SAGA raster value to points, a qual transforma o arquivo matricial em um arquivo vetorial composto por pontos correspondentes aos valores e posições dos pixels do raster original. Desta forma, tem-se acesso à tabela de atributos, ponto por ponto, ou seja, par por par de coordenadas.

Os valores foram, então, correlacionados no software Excel a partir do módulo de Análise de Dados, com a ferramenta de análise de Correlação. Conforme Ross (2004, p. 9), o coeficiente de correlação de amostra com duas variáveis pode ser entendido como "uma estatística que indica o grau em que um grande valor do primeiro membro do par tende a acompanhar um grande valor do segundo".

O coeficiente de correlação linear $(r)$ foi desenvolvido por Pearson tendo como objetivo indicar o grau de intensidade da relação entre duas variáveis. Ele pode ser positivo, quando a reta de correlação possui inclinação descendente, ou negativo, quando a reta possui inclinação ascendente. (CORREA, 2003, p. 108). Dessa maneira, tem-se que o valor de "r" varia entre $+1 \mathrm{e}-1$, indicando as situações seguintes:

- Quando $r=+1$, a correlação entre as variáveis é positiva;

- Quando $r=-1$ (a correlação entre as variáveis é negativa);

- Quando $r=0$ (não há correlação entre as variáveis ou, então, caso exista, a correlação não é linear),

Correa (2003, p. 109-110) ainda apresenta que, em termos práticos, podemse estabelecer os níveis de correlação entre variáveis da seguinte maneira: 
- quando $0<|r|<0,3$, a correlação é fraca e fica difícil estabelecer relação entre as variáveis;

- quando $0,3<|r|<0,6$, a correlação é fraca, porém, podemos considerar a existência de relativa correlação entre as variáveis;

- quando $0,6<|r|<1$, a correlação é de média para forte e a relação entre as variáveis é significativa, o que permite coerência com poucos conflitos na obtenção das conclusões.

As análises realizadas debruçaram-se, por conseguinte, em tais premissas a fim de se verificar, para os dois anos selecionados, os coeficientes de correlação entre as variáveis utilizadas no estudo, dadas pela imagem classificada e os IVs: SR, IVR, NDVI, e SAVI (para $L=0,5$ e $L=1,0$ ).

O índice SR é calculado através da equação:

$$
S R=\frac{I V P}{\mathrm{~V}}
$$

Onde:

- $\quad \mathrm{SR}$ = Índice de Vegetação da Razão Simples (Simple Ratio)

- $\quad I V P=$ Banda do Infravermelho próximo;

- $\quad \mathrm{V}=$ Banda do Vermelho.

Já o IVR pode ser expresso pela equação:

$$
I V R=\frac{V}{I V P}
$$

Onde:

- $\quad$ IVR = Índice de Vegetação da Razão (Ratio Vegetation Index - RVI)

- $\quad \mathrm{IVP}=$ Banda do Infravermelho próximo;

- $\quad V=$ Banda do Vermelho.

O NDVI é obtido através da formulação:

$$
N D V I=\frac{I V P-V}{\mathrm{IVP}+\mathrm{V}}
$$

Onde:

- $\quad$ NDVI = Índice de Vegetação da Diferença Normalizada (Normalized Difference Vegetation Index);

- $\quad \mathrm{IVP}=$ Banda do Infravermelho próximo; 
- $\quad \mathrm{V}=$ Banda do Vermelho.

O último índice utilizado foi o SAVI (Índice de Vegetação Ajustado ao Solo), cuja formulação é a seguinte:

$$
S A V I=\frac{(1+L) *(I V P-V)}{\mathrm{IVP}+\mathrm{V}+\mathrm{L}}
$$

Onde:

- $\quad$ SAVI = Índice de Vegetação Ajustado ao solo (Soil Adjusted Vegetation Index);

- $\quad \mathrm{IVP}=$ Banda do Infravermelho próximo;

- $\quad \mathrm{V}=$ Banda do Vermelho;

- $L=$ constante entre 0 e 1 ( $L=1$ para baixas densidades de vegetação e $\mathrm{L}=0$ para altas densidades). Foram utilizados os valores de $\mathrm{L}=1$ e $\mathrm{L}=$ 0,5 , uma vez que $L=0$ traduziria um índice idêntico ao NDVI.

\section{RESULTADOS E DISCUSSÕES}

As imagens geradas pelo índice SR para os anos de 1985 e 2018 podem ser observadas pelas figuras $2 \mathrm{a}$ e $2 \mathrm{~b}$. É importante ser ressaltado que as legendas, apesar de seguir um padrão de 10 (dez) cores, não expressam uma mesma escala de valores. De igual sorte foi adotado o modo de distribuição por quartil para a distribuição dos valores da escala de cores. Assim sendo, verifica-se que o maior valor encontrado para o índice SR em 2018, representado por uma cor intensa de verde na figura $2 b$, entendida como a vegetação dotada de maior biomassa, corresponde tão somente a uma coloração levemente esverdeada na figura $2 \mathrm{a}$, relativa ao ano de 1985.

Uma primeira análise indicaria, em decorrência, uma maior biomassa no ano de 2018. Isso não significa, entretanto, uma cobertura vegetal mais exuberante neste ano. Outra observação a ser feita diz respeito aos corpos d'água que, com os menores valores do índice, foram destacados do restante dos valores representados para melhor visualização. 
Figura $2 \mathrm{a}-\mathrm{SR}$ para o ano de 1985

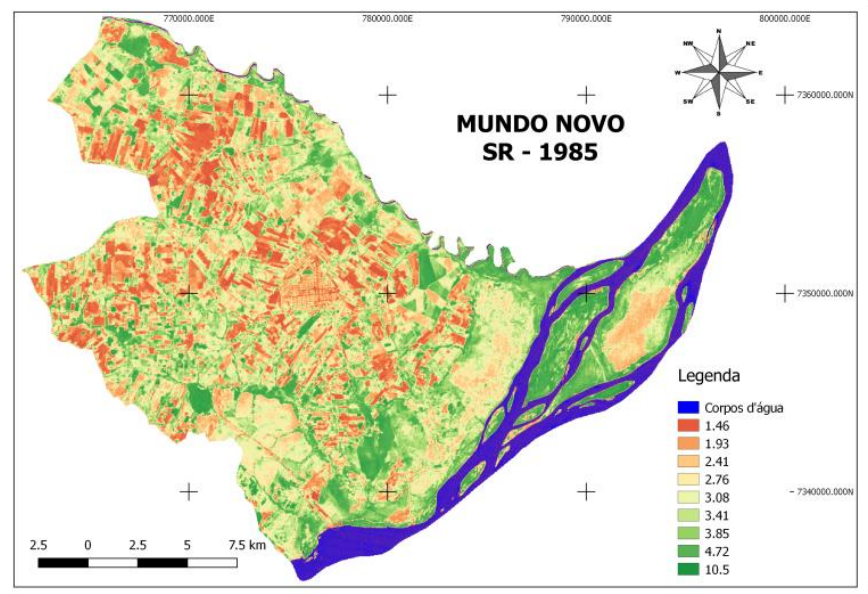

Figura $2 b-S R$ para o ano de 2018

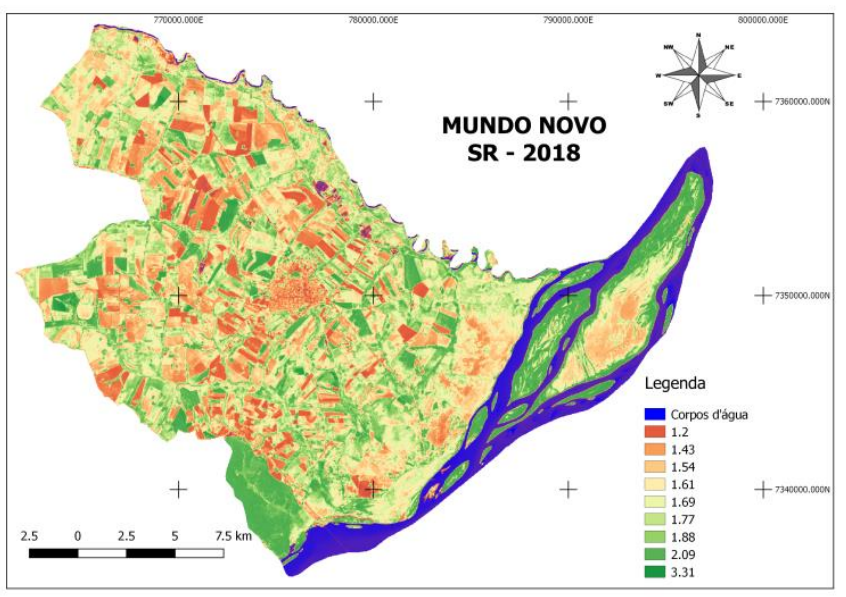

Fonte: Autor (2019).

O segundo índice utilizado foi o IVR. As imagens geradas pelo IVR para os anos de 1985 e 2018 podem ser conferidas pelas figuras 3a e 3b. Neste caso, deve ser salientado que as legendas seguem o padrão adotado para o SR, de 10 (dez) cores, as quais se apresentam invertidas com relação àquele índice em função de sua própria concepção. Novamente os "corpos d'água" foram realçados para melhor identificação.

Figura 3a - IVR para o ano de 1985

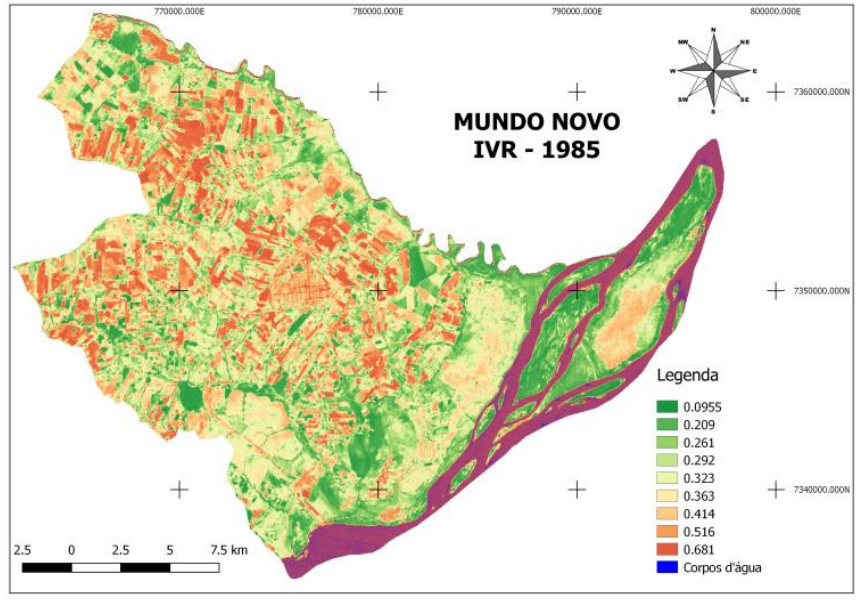

Figura 3b - IVR para o ano de 2018

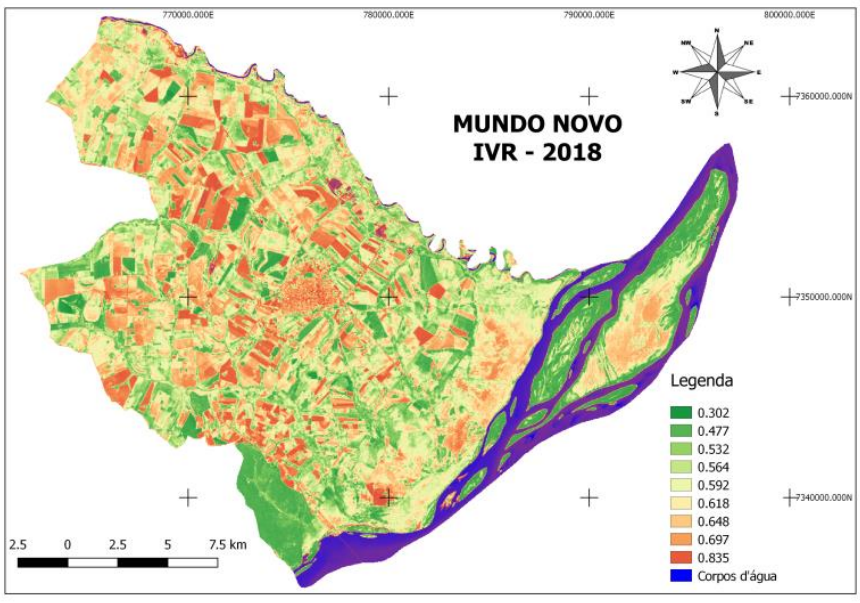

Fonte: Autor (2019)

O próximo índice calculado foi o NDVI (Índice de Vegetação Normalizado). As figuras 4a e 4b ilustram o NDVI para os anos de 1985 e 2018. Como pode ser observado nos mapas, verificam-se discrepâncias em relação aos valores das legendas para um e outro ano estudado. Outrossim, salienta-se que um valor de NDVI próximo de 1 (um) é indicativo de vegetação densa, com bastante biomassa. 
Figura 4a - NDVI para o ano de 1985

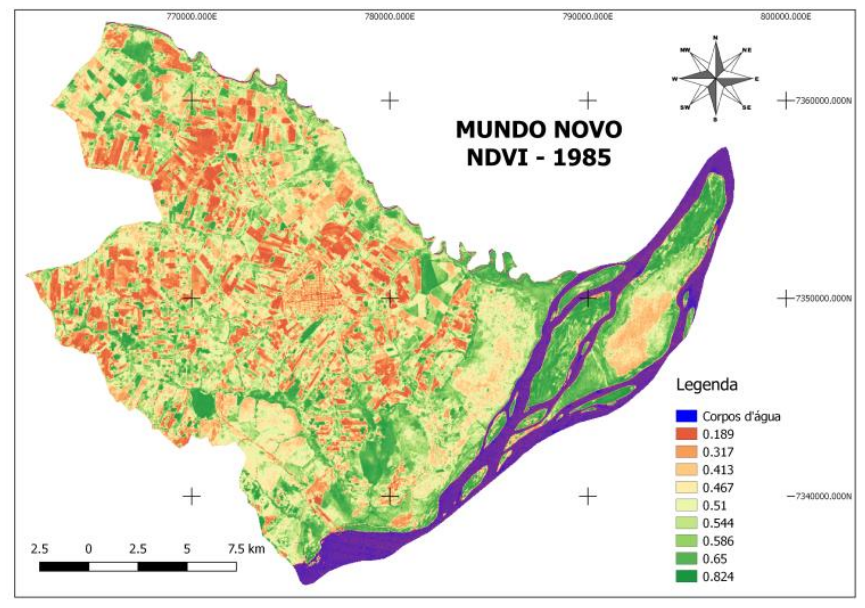

Figura 4b - NDVI para o ano de 2018

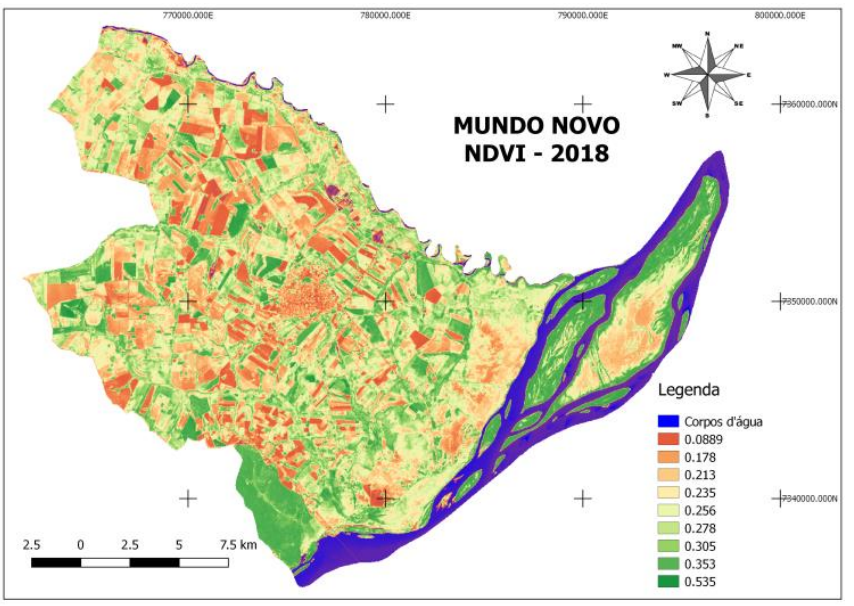

Fonte: Autor (2019)

Finalmente foi utilizado o SAVI (Índice de Vegetação Ajustado ao Solo). As figuras $5 a, 5 b, 5 c$ e $5 d$ reproduzem os mapas contemplando o SAVI para os anos de 1985 e 2018 com os valores de $L$ de 0,5 e 1,0.

Figura 5a - SAVI $(L=0,5)-1985$

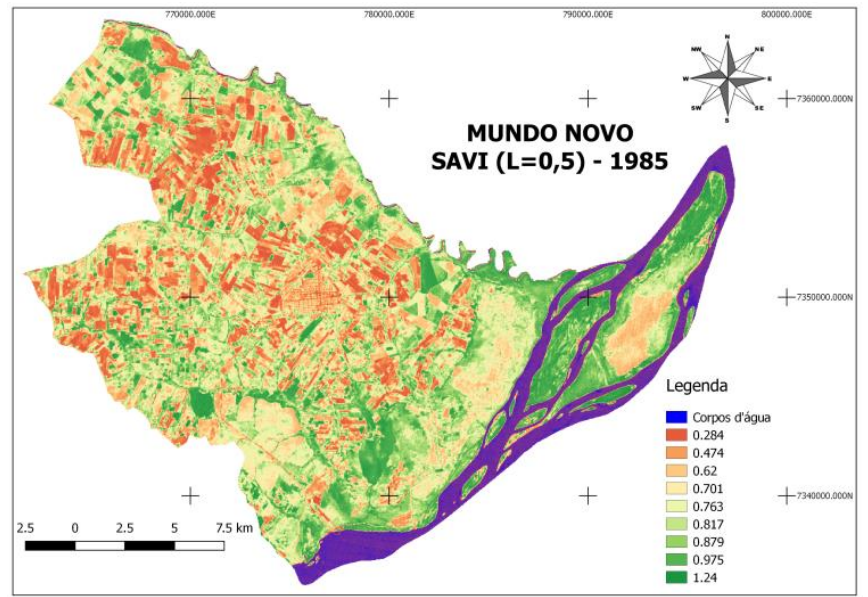

Figura 5c - SAVI $(L=1,0)-1985$

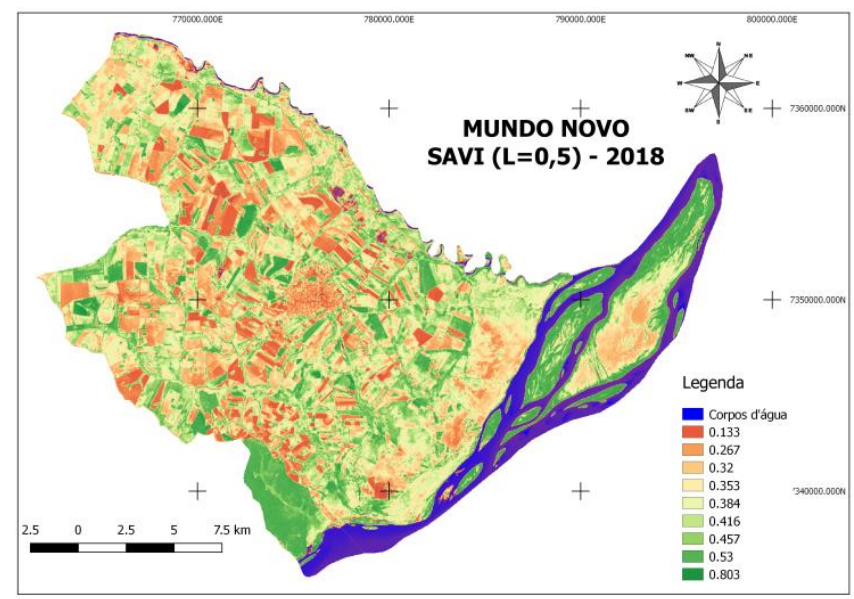

Figura 5b - SAVI $(L=0,5)-2018$

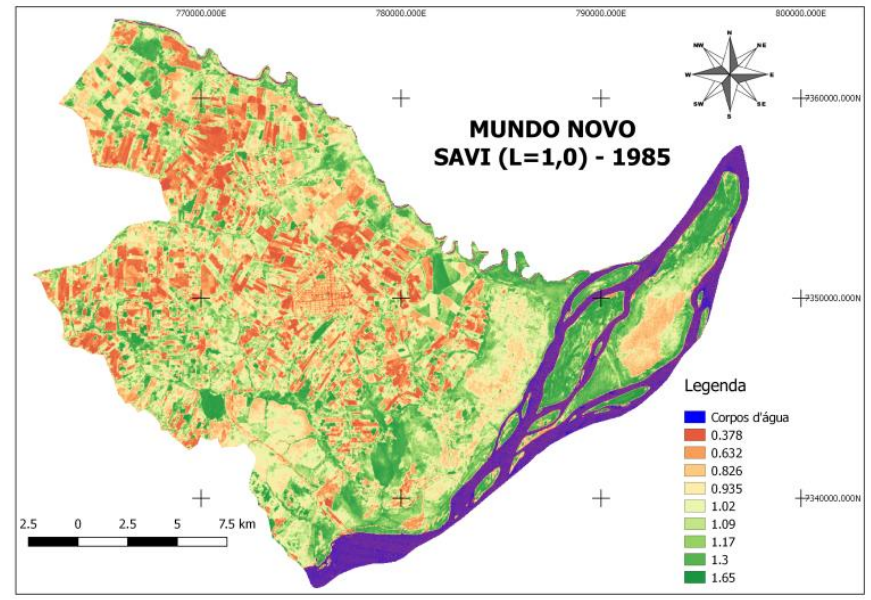

Figura 5b - SAVI $(L=1,0)-2018$

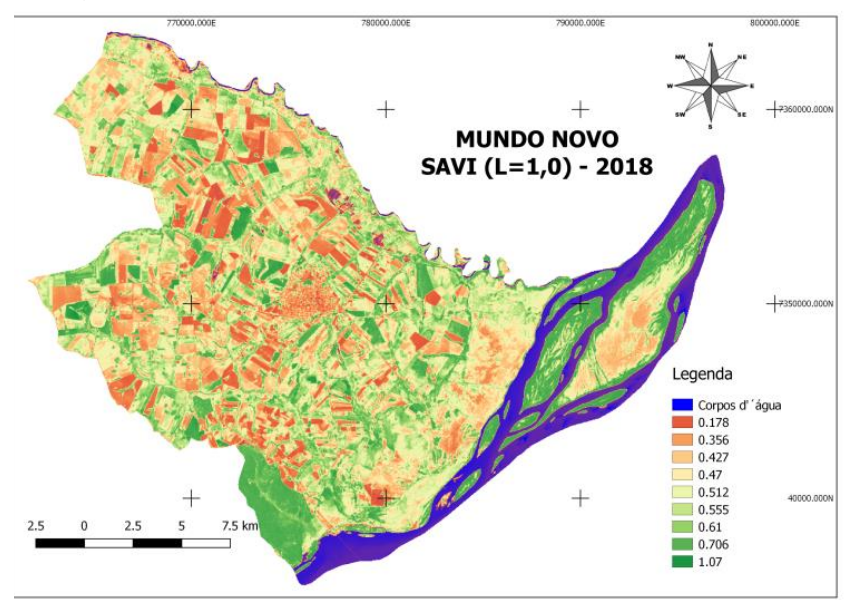

Fonte: Autor (2019).

Analisando as figuras, observa-se que a variação da constante "L" causa 
pequenas alterações nos mapas. As maiores transformações se deram em função das alterações temporais.

Realizada esta fase do experimento, como colocado anteriormente, os arquivos matriciais derivados da classificação supervisionada e dos IVs foram convertidos para arquivos vetoriais constituídos por pontos. As coordenadas " $\mathrm{x}$ ", " $\mathrm{y}$ " e o valor " $z$ " desses arquivos correspondiam exatamente aos valores dos pixels dos arquivos matriciais originais.

Os dados, em formato "Access" (.dbf), foram importados e retrabalhados no software Excel (2009). Cada um dos arquivos possuía 531.439 linhas, que contemplavam, além dos valores das coordenadas " $x$ " e " $y$ ", um identificador (ID), e o valor " $z$ " relativo ao pixel correspondente. No Excel, os dados foram correlacionados entre si e geraram as tabelas 1 e 2 , a seguir, que apresentam 0 valor "r" (coeficiente de Pearson) para mesmos.

Tabela 01 - Correlação dos dados para o ano de 1985

\begin{tabular}{|c|c|c|c|c|c|c|}
\hline & CLASSIFICAÇÃO & SR & IVR & NDVI & SAVIO5 & SAVI1 \\
\hline CLASSIFICAÇÃO & 1 & 0,714274793221 & $-0,695470348809$ & 0,750064659074 & 0,750063195719 & 0,750061709664 \\
\hline SR & 0,714274793221 & 1 & $-0,727030530774$ & 0,863424970178 & 0,863459534451 & 0,863494048753 \\
\hline IVR & $-0,695470348809$ & $-0,727030530774$ & 1 & $-0,965336040299$ & $-0,965312743367$ & $-0,965289458072$ \\
\hline NDVI & 0,750064659074 & 0,863424970178 & $-0,965336040299$ & 1 & 0,999999992748 & 0,999999971018 \\
\hline SAVI05 & 0,750063195719 & 0,863459534451 & $-0,965312743367$ & 0,999999992748 & 1 & 0,999999992760 \\
\hline SAVI1 & 0,750061709664 & 0,863494048753 & $-0,965289458072$ & 0,999999971018 & 0,999999992760 & 1 \\
\hline
\end{tabular}

Fonte: Autor (2019).

Tabela 02 - Correlação dos dados para o ano de 2018

\begin{tabular}{|c|c|c|c|c|c|c|}
\hline & CLASSIFICAÇÃO & SR & IVR & NDVI & SAVI 0,5 & SAVI 1,0 \\
\hline CLASSIFICAÇÃO & 1 & 0,671868716555 & $-0,718246624867$ & 0,712391240655 & 0,712389204942 & 0,712387169172 \\
\hline SR & 0,671868716555 & 1 & $-0,934590953221$ & 0,975592185289 & 0,975592910449 & 0,975593635667 \\
\hline IVR & $-0,718246624867$ & $-0,934590953221$ & 1 & $-0,989404040935$ & $-0,989403562634$ & $-0,989403084272$ \\
\hline NDVI & 0,712391240655 & 0,975592185289 & $-0,989404040935$ & 1 & 0,999999999988 & 0,9999999999951 \\
\hline SAVI 0,5 & 0,712389204942 & 0,975592910449 & $-0,989403562634$ & 0,999999999988 & 1 & 0,9999999999988 \\
\hline SAVI 1,0 & 0,712387169172 & 0,975593635667 & $-0,989403084272$ & 0,9999999999951 & 0,999999999988 & 1 \\
\hline
\end{tabular}

Fonte: Autor (2019).

Conforme pode ser observado a partir das tabelas, os IVs possuem alta correlação entre si, uma vez que os valores dos coeficientes de correlação se situam em faixas acima de 0,7, ou seja, com "r" acima de 70\%. De igual sorte, percebe-se 
a correlação negativa do IVR com relação aos demais elementos analisados, uma vez que se trata da operação inversa do SR. Merece ser destacado, igualmente, um quadro de correlação "quase perfeita" entre os índices NDVI e SAVI, tanto para $L=0,5$, quanto para $L=1,0$ para ambos os anos estudados.

A análise proposta neste estudo, entretanto, presumia a comparação dos IVs com a imagem classificada para os anos de 1985 e 2018. Como pode ser verificada, a correlação entre os IVs e a imagem classificada também é alta, ou seja, no geral, acima dos 70\%. Somente para o IVR em 1985 e SR em 2018 o valor encontrado para "r" fica ligeiramente abaixo de 0,7 (negativo para o IVR).

Os resultados obtidos aproximaram-se dos produtos obtidos em experimentos assemelhados utilizados em imagens Landsat, como os de Demarchi; Piroli; Zimback (2011), Rêgo et al. (2012); Oliveira et al.(2007), Almeida; Fontana (2009), Nonato; Rodrigues (2009) e Hentz et. al.(2014), entre outros, mas realizados para analisar diferentes IVs. Em geral, observa-se que há correlação entre os índices trabalhados pelos autores. Cabe ressaltar, no entanto, que o trabalho de Demarchi; Piroli; Zimback (2011) apresenta uma tentativa de comparar dois IVs (NDVI e SAVI) com uma classificação supervisionada pelo método de máxima verossimilhança. Neste caso, os autores concluem que

Os valores de porcentagem de cobertura vegetal mostraram-se semelhantes para os índices de vegetação NDVI e SAVI, mas um tanto discrepantes da porcentagem de cobertura vegetal estimada pelo método da classificação supervisionada por máxima verossimilhança. (DEMARCHI; PIROLI; ZIMBACK, 2011, p. 269)

A discrepância encontrada pelos pesquisadores é, de certa forma, consistente com os dados ora trabalhados. Entretanto, levando-se em consideração as ponderações de Correa (2003, p. 109-110), constatou-se que os valores encontrados possuem correlações de média a forte. Neste sentido, deve-se ter bastante cuidado quando de análises gerais de uma determinada área.

\section{Considerações finais}

Os dados trabalhados conduziram às seguintes conclusões:

- Como era de se esperar, todos os IVs apresentam correlação entre si e com a imagem classificada, tida como base para análise.

- Ocorreram pequenas oscilações entre os resultados obtidos com relação aos anos (1985 e 2018) apurados.

- O valor negativo encontrado para o " $r$ " referente ao IVR corresponde a 
correlações negativas deste índice com os demais dados tabelados.

- As correlações quase perfeitas entre os índices NDVI e SAVI devem-se às suas próprias concepções, uma vez que suas formulações são próximas uma da outra, com o SAVI contemplando variações na densidade de vegetação da área de estudo.

- Os valores do coeficiente de correlação "r" encontrados para a correlação entre a imagem classificada e os IVs, situados em torno de $70 \%$, denotam correlação entre as imagens; porém fogem ligeiramente às expectativas de uma correlação bem mais intensa entre as imagens. A partir disso, constata-se que os índices de vegetação não refletem a "realidade" do terreno quanto às três distintas classes adotadas: corpos d'água, ambientes antropizados e cobertura vegetal "original".

- A idealização dos IVs traduz as características e condições gerais da vegetação presente em dada região. Tais indicadores podem, entretanto, confundir porções com cultivos de plantas de pequeno ou médio porte com vegetação tida como nativa, ou original. De igual sorte, fragmentos de lavouras recém introduzidas, providas de intensa irrigação, podem coincidir com áreas alagadiças, e assim por diante.

- Para a caracterização das três classes concebidas, a classificação supervisionada mostra-se mais confiável do que quaisquer dos IVs testados.

- Os IVs são excelentes indicadores para estudos relativos ao monitoramento de áreas vegetadas específicas, contribuindo para análises temporais da situação das mesmas. Entretanto, devem ser trabalhados com bastante cuidado para não camuflar certos comportamentos.

- As imagens Landsat, mesmo que com pixel de $30 \mathrm{~m}$, foram satisfatórias para os propósitos deste experimento.

- Deve-se ter em mente que a possível ocorrência de precipitações pouco antes da captura das imagens pode mascarar certos resultados.

- Para se chegar o mais próximo possível da realidade, visitas a campo tornam-se indispensáveis, as quais podem ser acompanhadas com o uso de VANTs/drones e/ou de imagens de altíssima resolução.

Os resultados obtidos nesta pesquisa corroboraram as suposições empíricas relativas à possível correlação entre diferentes IVs e uma imagem classificada. Recomenda-se, outrossim, a repetição de tais experimentos para outras áreas e a 
inserção de outros índices. A experimentação em áreas mais ou menos florestadas poderá acarretar em correlações mais ou menos efetivas entre os IVs e a classificação realizada.

A inclusão de mais classes, quando da classificação supervisionada realizada, também poderá implicar na alteração dos produtos aqui apresentados. De igual sorte, a aplicação de outros métodos de classificação poderá acarretar em resultados distintos do apresentado neste estudo.

\section{REFERÊNCIAS}

ALMEIDA, Tatiana S. de., FONTANA, Denise C. Desempenho dos índices de vegetação NDVI e PVI para a cultura da soja em diferentes condições hídricas e de sistema de manejo do solo. Anais XIV Simpósio Brasileiro de Sensoriamento Remoto, Natal, Brasil, 25-30 abril 2009, INPE, p. 17-22. Disponível em http://marte.sid.inpe.br/col/dpi.inpe.br/sbsr\%4080/2008/11.18.01.30/doc/17-22.pdf. Acesso em: 21/06/2018.

CORREA, Sonia Maria B. B. Probabilidade e Estatística. 2 ed. Belo Horizonte: PUC Minas Virtual, 2003. Disponível em: http://www.inf.ufsc.br/ vera.carmo/LIVROS/ LIVROS/livro probabilidade estatistica 2a ed.pdf. Acesso em: 22/06/2019.

CRÓSTA, A. Processamento Digital de Imagens de Sensoriamento Remoto. Campinas: Unicamp, 1993.

DEMARCHI, Julio C., PIROLI, Edson L., ZIMBACK, Célia R. L. Análise temporal do uso do solo e comparação entre os índices de vegetação NDVI e SAVI no município de Santa Cruz do Rio Pardo - SP usando imagens Landsat-5. RA'EGA. V. 21. Curitiba, 2011. P. 234-271. Disponível em: https://revistas.ufpr.br/raega/issue/archive. Acesso em 06/07/2018.

EASTMAN, J. Ronald. IDRISI for Windows: Introdução e exercícios tutoriais. Porto Alegre, RS: Centro de Recursos Idrisi Brasil - UFRGS, 1998.

Excel. Windows Versão 7: Microsoft Corporation, 2009. CD.

FITZ, Paulo R. Geoprocessamento sem complicação. São Paulo: Oficina de Textos, 2008.

FITZ, Paulo R. VIEIRA, Jeferson C. SOARES, Mirlla C. O uso de polígonos de amostragem em classificações supervisionadas de imagens de satélite. Entre-Lugar. V. 10; N.19. Dourados, 2019. P. 319-342. Disponível em: http://ojs.ufgd.edu.br/index.php/entre-lugar/article/view/9595. Acesso em 10/08/2019.

HENTZ, Ângela M. K., RUZA, Marieli S., DALLA CORTE, Ana P. SANQUETTA, Carlos R. Técnicas de sensoriamento remoto para estimativa de biomassa em ambientes florestais. Enciclopédia Biosfera. V. 10, N. 18. Goiania, 2014, p. 2810-2823. Disponível em http://www.conhecer.org.br/enciclop/2014a.htm. Acesso em:11/05/2019.

HUETE, A. R., LIU H. Q., BATCHILI, K., LEEUWEN, W. van. A Comparison of Vegetation Indices over a Global Set of TM Images for EOS-MODIS. Remote sensing environ. V. 59, p. 440-451. New York: Elsevier Science Inc., 1997. Disponível em: https://www.academia.edu/15285630/A

comparison of vegetation indices over a global set of TM images for EOS-MODIS. Acesso em: 11/05/2019. 
IBGE. Censo Demográfico, 2010. Disponível em www.ibge.gov.br. Acesso em 15/08/2018. IBGE. Censo Agropecuário, 2006. Disponível em www.ibge.gov.br. Acesso em 15/08/2018. IBGE. Censo Agropecuário, 2017. Disponível em www.ibge.gov.br. Acesso em INPE. Instituto Nacional de Pesquisas Espaciais. Imagens do satélite Landsat. Disponíveis em www.inpe.br. Acessos entre julho de 2018 e janeiro de 2019.

$15 / 08 / 2018$.

MATO GROSSO DO SUL. Semagro. Zoneamento Ecológico-Econômico do Estado do Mato Grosso do Sul - ZEE-MS. 2009. Disponível em: http://www.semagro.ms.gov.br/zoneamento-ecologico-economico-de-ms-zee-ms. Acesso em: 17/08/2018.

NONATO,Robson T., RODRIGUES, Luiz H. A. O efeito da utilização de diferentes índices de vegetação na classificação de imagens digitais pela aprendizagem por árvore de decisão. Anais XIV Simpósio Brasileiro de Sensoriamento Remoto, Natal, Brasil, 25-30 abril 2009, INPE, $\quad$ p. $\quad 997-1004 . \quad$ Disponível http://marte.sid.inpe.br/col/dpi.inpe.br/sbsr\%4080/2008/11.17.08.18/doc/997-1004.pdf Acesso em: 21/06/2018.

OLIVEIRA, Luís G. L. de., PEREIRA, Leonardo M., PEREIRA, Gabriel, MORAES, Elisabete C. Estudo da variabilidade de índices de vegetação através de imagens do ETM+/LANDSAT 7. Anais XIII Simpósio Brasileiro de Sensoriamento Remoto, Florianópolis, Brasil, 21-26 abril 2007, INPE, p. 5995-6002. Disponível em: http://marte.sid.inpe.br/col/dpi.inpe.br/sbsr@80/2007/01.1.19.10/doc/@sumario.htm. Acesso em: 11/05/2019.

PORTELA, Nara Miranda. Modelo de mistura de gaussianas fuzzy contextual. Tese (Doutorado) - Universidade Federal de Pernambuco. UFPE: Recife, 2015. Disponível em: https://repositorio.ufpe.br/handle/123456789/16818. Acesso em: 22/06/2019.

QGIS/SAGA. versão 2.18 - Las Palmas de G.C, 2018. Disponível em: https://qgis.org/en/site/. Acesso em 01/03/2018.

RÊGO, Shirley C. A., LIMA, Priscila P. S. de., LIMA, Maria N. S., MONTEIRO, Thereza R. R. Análise comparativa dos índices de vegetação NDVI e SAVI no município de São Domingos do Cariri-PB. Geonorte. Edição Especial, V. 2 N. 4. Manaus, 2012, p. 12171229. Disponível em https://www.periodicos.ufam.edu.br/revista-geonorte . Acesso em 21/06/2018.

RICHARDS, John A.; JIA, Xiuping. Remote Sensing Digital Image Analysis: An Introduction. 4 ed. Berlin: Springer-Verlag, 2006.

ROSS, Sheldon M. Introduction to Probability and statistics for engineers and scientists. 3 ed. San Diego: Elsevier, 2004.

SCHMIDT, H.; KARNIELI, A. Sensitivity of vegetation indices to substrate brightness in hyper-arid environment: the Makhtesh Ramon Crater (Israel ) case study. International Journal of Remote Sensing, 2001. vol. 22; no. 17, p. 3503-3520. Disponível em: http://www.tandf.co.uk/journals. Acesso em 10/05/2019.

USGS. U.S. Geological Survey Imagens do Satélite Landsat. Disponíveis em https://www.usgs.gov/. Acesso entre julho de 2018 e janeiro de 2019.

XUE, Jinru; SU, Baofeng. Significant Remote Sensing Vegetation Indices: A Review of Developments and Applications. Journal of Sensors. Volume 2017, Article ID 1353691, 17 pages. Disponível em:https://doi.org/10.1155/2017/1353691. Acesso em 10/05/2019. 


\section{NOTAS DE AUTOR}

\section{CONTRIBUIÇÃO DE AUTORIA}

Paulo Roberto Fitz - Concepção. Coleta de dados, Análise de dados, Elaboração do manuscrito, revisão e aprovação da versão final do trabalho

\section{FINANCIAMENTO}

Não se aplica.

\section{CONSENTIMENTO DE USO DE IMAGEM}

Não se aplica.

\section{APROVAÇÃO DE COMITÊ DE ÉTICA EM PESQUISA}

Não se aplica.

\section{CONFLITO DE INTERESSES}

Não se aplica.

\section{LICENÇA DE USO}

Este artigo está licenciado sob a Licença Creative Commons CC-BY. Com essa licença você pode compartilhar, adaptar, criar para qualquer fim, desde que atribua a autoria da obra.

\section{HISTÓRICO}

Recebido em: 05-09-2019

Aprovado em: 25-06-2020 